\author{
Jean-Michel Jeannin
}

Einleitung

Opuntia ssp. (Fam. Cactaceae) sind in Amerika heimisch. Verschiedene Arten sind vom Menschen absichtlich oder unbeabsichtigt anderweitig eingeführt worden; die zwei hier besprochenen Arten z.B. auf die Kanarischen Inseln, namentlich Teneriffa. Opuntia ficus-indica (L.) Mill. bildet grosse Sträucher mit fleischigen, flachen, eiförmigen bis länglichen graugrünen Stängelgliedern von 20-60 cm Länge. In den Blattachseln findet man Polster von Borsten («Glochiden») und bis zu 2 kräftige, 2,5 cm lange Dornen. Die gelben Blüten befinden sich meistens am Rand der Stängelglieder. Die Früchte sind gelb-orange, gleichen Feigen und sind essbar. Wegen ihrer Borstenpolster müssen sie mit Vorsicht geschält werden [1]. Opuntia dillenii (Ker-Gawl.) Haw bildet niedrige, ausgebreitete Sträucher. Die Stängelglie-

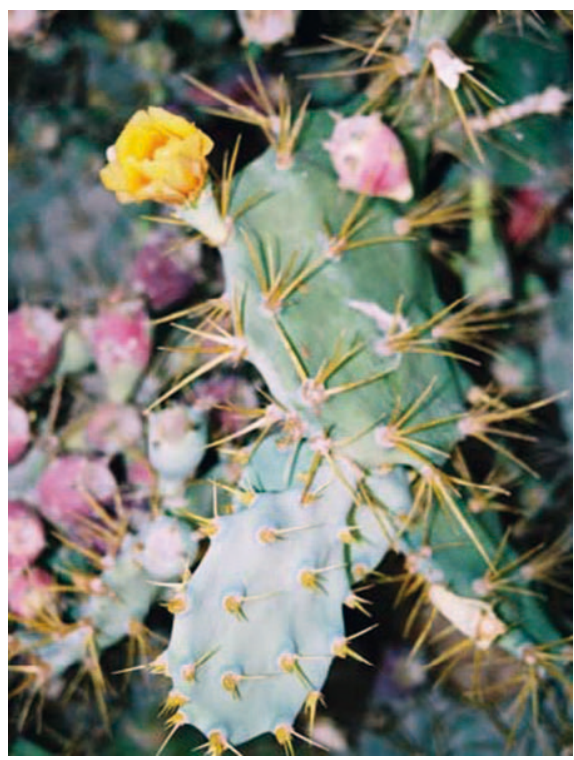

Abb. 1. O. dillenii, Blüte und zum Teil unreife Früchte. Teneriffa 2006

\title{
Exotische Heilpflanzen (5)
}

\author{
Opuntia dillenii (Ker-Gawl.) Haw; Opuntia ficus-indica (L.) Mill.
}

der sind eiförmig bis rundlich und werden bis $40 \mathrm{~cm}$ lang. Der Kaktus ist stark mit gelb und braun gebänderten oder gefleckten Dornen bewehrt. Die Blüten sind zitronengelb, die purpurnen Früchte kugelig oder birnenförmig. Auch die Früchte von O. dillenii sind essbar $[1,2]$.

\section{Verwendung als Heilpflanze}

O. dillenii wird in der mexikanischen Volksmedizin zur Behandlung von Prostatabeschwerden und auf Teneriffa zur Senkung des Glucosespiegels bei Diabetes mellitus verwendet [3]. In Israel wird ein Dekokt aus den Blüten von $O$. ficus-indica als stark wirksames Diuretikum verwendet [4]. Neuere Forschungsarbeiten befassen sich mit der antihyperglykämischen Wirkung der Früchte von $O$. dillenii [3], der Behandlung der gutartigen Prostatahyperplasie mit einer Zubereitung aus den Blüten von O. ficus-indica [4] oder der antiphlogistischen Wirkung der Blüten von O. dillenii [5].

\section{Weitere Verwendungsmöglichkeiten}

Auf Teneriffa wurde im 19. Jahrhundert O. ficus-indica zur Züchtung der Cochenille-Schildlaus kultiviert, aus welcher der Farbstoff Karminrot extrahiert wurde. Dazu wurden die Läuse von den Opuntien weggeschabt und dann gemahlen. Mit der Erfindung eines synthetischen Karmins ist diese Produktion zusammengebrochen. Neuerdings werden der Fruchtsaft und das Fruchtfleisch als Farbstoff für Lebensmittel und für Medikamente verwendet [6]. Die Früchte sowohl von O. dillenii als auch von O. ficus-indica («prickly pear») werden als Obst zum Verzehr angeboten [3]. Selten einmal werden alte Stängelglieder Kühen und Schafen verfüttert, nachdem man die Dornen abgebrannt hat [6].

\section{Phytochemie}

Charakteristische Substanzen von O. dillenii sind die Betalaine, Ausgangssubstanzen der Betacyane und der Betaxanthine (z.B. Indicaxanthin). Letztere verleihen den Blüten ihre gelbe Farbe. Die Blüten enthalten weitere Flavonole. In den Cladoden wurden a-Pyrone, z.B. Opuntiol, und verschiedene Steroide gefunden. Die Früchte weisen Catechin und Epicatechin auf. Die getrockneten Kerne enthalten 7,5\% Öl. O. ficus-indica enthält Taurin, eine Aminosäure, die nur selten in Pflanzen vorkommt [6].

\section{Literatur}

1 Schönfelder P, Schönfelder I: Die KosmosKanarenflora, ed 1. Stuttgart, Franckh-Kosmos, 1997.

2 Fischer M, Kuss P, Stöcklin J: Neophytische Opuntien im Sukkulentenbusch. Bauhinia 2007;20:35-44.

3 Perfumi M, Tacconi R: Antihyperglycemic effect of fresh Opuntia dillenii fruit from Tenerife (Canary Islands). Int J Pharmacognosy 1996;34:41-47.

4 Palevitch D, et al: Treatment of benign prostatic hypertrophy with Opuntia ficus-indica (L.) Miller. Int J Alternative \& Complement Med 1994;21.

5 Ahmed MS, et al: Antiinflammatory flavonoids from Opuntia dillenii (Ker-Gawl) Haw. Flowers growing in Egypt. Phytother Res 2005;19:807809

6 Böhm H: «Opuntia dillenii» - an interesting and promising Cactaceae taxon. J PACD 2008;10:148-170.

\section{KARGER}

Fax +497614520714 Information@Karger.d www.karger.com (c) 2010 S. Karger GmbH, Freiburg
Dipl. med. biol. Jean-Michel Jeannin Holeestrasse 43, 4054 Basel, Schweiz

Tel. +41 61-4215991, Fax -4230313

jmjeannin@dataworks.ch 